\title{
Analyzing business management and technology characteristics of small and medium sized architectural design firms in Turkey
}

\author{
Suat Günhan \\ College of Architecture, Construction Science and Management Program, The University of Texas at San Antonio USA. \\ E-mail: suat.gunhan@utsa.edu. Tel: +1 (210) 458-8131. Fax: +1 (210) 458-3091. \\ Accepted 27 May, 2011
}

\begin{abstract}
Globalization affects the way business is conducted. The worldwide openness of the markets creates both opportunities and threats for local companies. To survive and prosper in the new economic system, companies will need to develop new strategies. Therefore, analyzing the business and technology characteristics of small to medium size firms is critical in order to develop strategies to facilitate their integration to globalization. The paper presents the technology and business characteristics of small and medium sized (SMEs) architectural design firms in Turkey. The findings related to firms' strengths include that SMEs can adopt new technologies as long as commercial benefits are evident, that they are well aware of the importance of business development skills, and that they have an extensive partnership experience as well as some strategic planning culture. The findings related to firms' weaknesses indicate that SMEs lack the necessary skills to manage organizational growth, do not use project management software extensively, are not actively involved in new and effective project management technologies, and display low levels of specialization.
\end{abstract}

Key words: Architectural firms, small and medium sized (SMEs), Turkey, business management, globalization.

\section{INTRODUCTION}

The globalization of business brings new opportunities for architecture, engineering, construction (AEC) firms in fast developing economies. In this economic system, the integration of small and medium-sized enterprises (SMEs) into the global business system becomes critical. SMEs are responsible for substantial amount of employment therefore their success has a direct impact on the economy of the country in which they operate.

Fast developing economies like Turkey experience large volume of design and construction work due to the increase in purchasing power and interest of foreign investors. International companies usually prefer establishing partnerships with local AEC firms in order to deal with the complexities in local markets. When large international companies expand their business into new international markets, they continue to work with the same construction company that they worked in their domestic projects. While this situation creates opportunities for those AEC firms, at the same time, the need for local partners in host countries is also recognized (Mawhinney, 2001).

Many local SMEs are engaged as subcontractor firms or in different forms of partnership with the entrant firms. The local SMEs benefit from this situation unless they possess adequate business and technology skills. In order to be part of the global business system, the SMEs need to improve these skills. In this study, the business and technology characteristics of architectural design SMEs are identified and analyzed. Following that analysis, discussions and recommendations are provided.

\section{LITERATURE REVIEW}

The contribution of SMEs to total employment is quite high (Knight, 2001). Langford and Male (2001) reports that, $90 \%$ of all operating firms in the industry are SMEs. Larger firms are about $1 \%$ of the total number but they undertake majority of the workload. Despite the workload, 
most SMEs fall behind the larger firms in terms of capabilities, market power and many other resources (Knight, 2000). In today's business environment, no business is isolated and safe from global competition. Global competition is required for all firms at all levels (Root, 1994).

SMEs' role is highly important for Turkey's economy. They account for $99.8 \%$ of total enterprises, and $77 \%$ of total employment (Gursoy, 2006). Despite these numbers, SMEs only contribute to $28 \%$ of all economic activity (TUSIAD Report, 2002).

According to Yilmaz (2003), the major handicaps for SMEs in all business sectors in Turkey are that the firms are too small and they operate with low efficiency, inadequate market knowledge, low technology skills, inefficient project management processes, lack of basic skills in business development, lack of standardization in manufacturing, low specialization, and low potential of exporting. According to OECD Report (2004), the fundamental weaknesses of SMEs in Turkey are insufficient know-how and low technology level, and access to finance. The findings of Aktas (2006) supports these handicaps that the SMEs in Turkey have low level of technology and they do not use information technology efficiently, they lack appropriate marketing, managerial, project management and communication skills. In addition to these findings, Aktas (2006) also mentioned that the ability to make strategic planning is not well developed.

The business management characteristics of the SMEs in architectural design business can be analyzed within some of these factors. This way, it is possible to observe the degree of weakness and strength in the context of chosen factors. In order to choose applicable factors to analyze, first the nature of architectural design services must be defined. Depending on a project delivery method, architects have different contractual relationships with other project stakeholders. Contracts define the expectations from an architectural design. Architectural design is expected to meet not only functional, aesthetic, and technical requirements but also time, budget, constructability, and quality requirements. These expectations require technological abilities and effective organizational setup within the architectural design firm. Therefore, technology and project management skills need to be explored. In addition to these factors, business development and marketing related issues need to be explored as well.

\section{Technology and project management}

The most important technology required in today's architectural design environment is computer aided drafting design (CADD) based technologies. Improved CADD based technologies do not only facilitate the production of drawings but also facilitate the integration of project participants and change the way that the projects are delivered. CADD technologies were developed into to building information modeling (BIM) which can be defined as "the digital representation of physical and functional characteristics of a facility" according to the National Institute of Building Science (Interoperability Report, 2007). Improved CADD technologies allow firms to improve their work quality, therefore, obtaining a better organizational infrastructure for their integration to global business standards. In addition to technology use, it is important to explore firms' attitudes towards project management practices. According to Jones (2001), project management optimizes to meet the project objectives in a timely manner, within budget and expected quality which are equally important as design. Project administration methods affect the effectiveness of the business operations. The existence of an established project administration system enhances the working mechanism of a project. The AEC industry in nature is highly dependent on the external stakeholders' input during the execution stage.

Therefore, the success of the project is dependent on the successful integration of diverse participants to project process. Today's projects are technologically complex and more input is required from diverse project stakeholders. The level of involvement in information communication technology (ICT), such as the availability of a web based project management system (WPMS), is an important feature that needs to be analyzed. ICT substantially improves project management environment by facilitating the collaboration among project participants. According to Rojas and Songer (1999), the use of ICT improves the effectiveness of a project. Nitithamyong and Skibniewski (2004) noted that the ICT improves firms' capabilities and enhances the abilities to compete globally. The improvements in technology have also promoted the clients' sophistication and they are more demanding in technology use during the project delivery process (Jones, 2001). Therefore, architectural firms are not only expected to use technology to facilitate their services but also to meet clients' expectations in the project process.

\section{Marketing and business development}

The AEC industry has relatively less involvement with marketing and business development as compared to accountants, lawyers, medical practitioners and other licensed professionals (Babiarz, 2000). According to Katsanis and Katsani (2001), the AEC industry involvement has lagged behind when it comes to adopting contemporary marketing strategies despite operating within a very competitive business environment. In addition to this, only few design professionals (architects) see their field as a business, mainly because they are trained as designers and many 
of them see marketing as not being close to their practice (Jones, 2001). On the other hand, Jones (2001) also adds that a survey performed among architects both from public and private sectors indicates that more than $86 \%$ of the participants confirmed that architects should be more active in marketing and business development aspects of their practice. Considering the facts on marketing, if a smaller firm has an established systematized approach towards marketing and business development, this can be considered positive for that firm's future development, and its ability to compete globally. In addition to business development and marketing, strategic planning and management issues receive less attention in AEC industry, especially at SMEs level, due to daily project level challenges (Chinowsky, 2001). Thus, the existence of strategic planning process is an indication that the firm is aware of the effects of internal (strengths and weaknesses) and external environments (threats and opportunities) on the firm.

\section{RESEARCH METHODOLOGY}

A survey questionnaire was administered to the architects participating in continuing education courses taught in four of the larger cities in Turkey. Two hundred and thirty two architects participated in a questionnaire survey. The participation was on a voluntary basis.

The questionnaire survey is composed of three parts. The first part aims to collect general information about the firms such as the age of the firm, number of professionals employed, years of professional experience, types of projects (building segments) and geographical scope. The size of the firms is measured in terms of number of professionals employed, rather than revenues. The second part is about technology and project management issues. The questions assess firms' involvement in CADD technologies, project management software, ICT and a systematic approach to project administration. The third part is about marketing and business development. The questions are about contracting methods, the methods of acquiring new projects, the way client presentations are handled, partnership situations, professional memberships, the way networking is maintained and developed, whether the firm treats business development as a separate function, existence of marketing research, the use of client tracking programs, and basic questions to find out if basic strategic planning concepts are included in the firms' agendas.

\section{FINDINGS AND ANALYSIS}

The age of the participant firms range between 1 and 39 . The number of professionals employed in these firms range between 2 and 28 and the total years of experience averaged 18 years. The average firm age was 13 ranging between 1 and 39 (Table 1). The average number of employed professionals (including the business owner) in the firms was 2.7, ranging between 2 and 28 (Table 1). This finding implies that the respondents' firms are small and medium sized. The respondents' total years of experience in the industry averaged 18 years lending credibility to the answers. In terms of building specialty, 228 firms were involved in residential building, 162 in commercial building, 84 in industrial building, and 80 in interiors whereas 30 firms were active in all building segments, 155 firms were active in both residential and commercial segments. Residential projects appear to dominate the market of architectural design SMEs participating in the survey. In terms of geographical scope, 143 firms operated locally, 29 regionally, and 7 nationally. Only one firm operated at the international level. As expected, the results indicate that SMEs have strong local presence.

\section{Analysis of technology and project management}

Two hundred six out of 232 firms (89\%) were involved with CADD technologies. Considering that the average number of professionals working in these firms was only 2.7, the level of CADD technology involvement is high. On the other hand, the use of project management software use was quite low. Only 23 out of 232 firms $(10 \%)$ were using project management software in their operations. Not surprisingly, exposure to web based project management was also low (7.3\%). The low usage of project management software indicates that project management skills are not in demand in the market served by SMEs. This result is important since it gives an important hint about the market's perception about the capabilities of SMEs. It can also be interpreted that profit margins are relatively higher in developing countries than in industrialized countries because using sophisticated project management tools is critical if profit margins are tight due to fierce competition. While finishing a project on schedule, within budget and within the required quality is the ultimate goal of all AEC firms, the methods of accomplishing this goal may vary depending on the respective countries' social, cultural, and economic dynamics. The perfect example for this is that in newly industrialized and developing countries, wages are lower and therefore projects can be completed without major cost drawbacks. This finding agrees with Sarshar and Isikdag's (2004) study that indicates that time-saving technology and management applications are not well established in Turkey because of lower wages. But the fact that the diffusion of CADD was very high, it demonstrates that the use of project management software can also be easily adopted in the industry. This can be achieved if project management related courses and related software application demonstrations are included in architecture, civil engineering and related fields' curricula, and are encouraged by professional societies. One of the major indications of the effectiveness of project management is the existence of a robust project administration structure and well established procedures. The related question to ask include "Does your firm have a formal administrative 
Table 1. General information.

\begin{tabular}{lcc}
\hline Information & Frequency & Percentage \\
\hline Age of Firm & & \\
Less than 5 years & 50 & 21.55 \\
5 to 10 years & 52 & 22.41 \\
11 to 20 years & 80 & 34.48 \\
More than 20 years & 50 & 21.55 \\
& & \\
Number of professionals employed & & \\
1 to 5 professionals & 224 & 96.55 \\
6 to 10 professionals & 7 & 3.02 \\
11 to 20 professionals & - & - \\
More than 20 professionals & 1 & 0.43 \\
& & \\
Respondent's years of experience in AEC Industry & & \\
Less than 5 years & 11 & 4.74 \\
5 to 10 years & 41 & 17.67 \\
11 to 20 years & 78 & 33.62 \\
$21-30$ years & 61 & 26.29 \\
$31-40$ years & 20 & 8.62 \\
More than 40 years & 1 & 0.43 \\
No answer & 20 & 8.62 \\
\hline
\end{tabular}

structure when running projects and does your firm conduct regular meetings (weekly or bi-weekly) with the external project stakeholders during the execution of projects?" The existence of meetings is particularly important because it is a major indicator that coordination of project management activities is taken seriously for effective project management. One hundred fifty out of 232 firms (64\%) indicated that they had a formal administrative structure and that they held regular meetings with different parties during the execution of projects. The absence of formal project administration procedures in approximately one third of the participating firms is an indication of poor management practice. It can be speculated that these firms establish internal project administration procedures but exclude stakeholders from these procedures.

\section{Analysis of business development and marketing}

The participants were also asked about the ways of getting new contracts. Understanding the way of getting new contracts is important in order to understand the business culture within SMEs in architectural design services. Having a consistent portfolio of repeat clients is important as it allows a firm to position itself for the long run. The better scenario includes frequently adding new clients into a firms' portfolio while maintaining the existing client portfolio. The most common method of getting new contracts was through "repeat client" (216 firms, 93\%) followed by being invited to compete against a set of preselected firms ( 45 firms, $19 \%$ ). The lump sum alternative was the third common way of being involved in new contracts (14 firms, $6 \%$ ). This result indicates that a well structured business development approach is not yet established in SMEs in the architectural design services. When asked whether participants' firms treated business development as a separate function, 41 firms (18\%) confirmed that they had a formal Business Development Department that exclusively undertakes marketing tasks (Table 2). In 131 of the remaining 191 firms, the business development task was handled by the owner or a partner. Considering that the average number of working professionals in responding firms is only 2.7 , the number of firms with business development departments 41 $(18 \%)$ is quite high. But still, there is a need for business development oriented minds in smaller firms. Relying heavily on "repeat clients" is not enough for long-term growth. Architecture curricula in universities in Turkey do not cover business development and marketing related topics. But the importance of marketing is well appreciated in practice. There needs to be an extra effort in SMEs in the architectural design business to develop such thinking.

The respondents were asked about how much time they allocated for project presentation preparations as part of business development (Table 2). Most firms (84\%) spent not more than a week, enough to make professional 
Table 2. Survey results: Marketing and business development.

\begin{tabular}{|c|c|c|}
\hline Information & Frequency & Percentage \\
\hline \multicolumn{3}{|l|}{ Business development } \\
\hline The firm owner or partner is in charge of business development & 131 & 56 \\
\hline The Business Development Department is in charge & 41 & 18 \\
\hline Other & 5 & 2 \\
\hline No answer & 55 & 24 \\
\hline \multicolumn{3}{|l|}{ Time Spent in preparing for Project Presentations } \\
\hline 1 to 3 days & 109 & 47 \\
\hline 1 week & 87 & 37 \\
\hline 2 weeks & 23 & 10 \\
\hline More than 2 weeks & 2 & 1 \\
\hline Depends on the project & 2 & 1 \\
\hline No time spent on presentations & 5 & 2 \\
\hline No answer & 4 & 2 \\
\hline \multicolumn{3}{|l|}{ Marketing research } \\
\hline $\begin{array}{l}\text { The respondent has performed at least once, a questionnaire survey, } \\
\text { market analysis etc. to understand market conditions and develop sound } \\
\text { strategies }\end{array}$ & 108 & 47 \\
\hline No marketing research & 124 & 53 \\
\hline \multicolumn{3}{|l|}{ Client tracking programs } \\
\hline The firm has a client tracking system & 72 & 31 \\
\hline $\begin{array}{l}\text { The firm does not have a client } \\
\text { tracking system }\end{array}$ & 156 & 67 \\
\hline No answer & 4 & 2 \\
\hline \multicolumn{3}{|l|}{ Partnership experience } \\
\hline The respondent currently has a partner(s) & 104 & 45 \\
\hline The respondent had partners before & 43 & 18 \\
\hline The respondent never had partners & 85 & 37 \\
\hline \multicolumn{3}{|l|}{ Networking } \\
\hline The respondent has an active role in the Chamber of Architects & 36 & 15 \\
\hline The respondent has membership in social clubs/organizations & 100 & 43 \\
\hline The respondent has active roles in social clubs/organizations & 48 & 21 \\
\hline No answer & 48 & 21 \\
\hline \multicolumn{3}{|l|}{ Strategic planning culture } \\
\hline The firm performs strategic planning & 145 & 63 \\
\hline The respondent does not perform strategic planning & 79 & 34 \\
\hline No answer & 8 & 3 \\
\hline
\end{tabular}

presentations.

When it comes to marketing research, participants were asked if they had conducted research (questionnaire survey, market analysis, etc.) to understand clients' needs and expectations (Table 2). It was interesting to note that despite the small average size of firms, almost half $(47 \%)$ routinely undertook marketing research. Participants were also asked if they had a client/prospective client tracking program (Table 2). It looks like client tracking is less popular than marketing research in SMEs. Respondents overwhelmingly agreed $(80 \%)$ that curricula in architecture and related fields should include business development and marketing related courses. They also agreed that business 
development skills have equal importance compared to design and technology skills.

\section{Partnership experience and networking}

Survey indicated that (Table 2) 128 out of the 232 respondents $(55 \%)$ were sole owners but that 43 out of those 128 firms had partners before. This means that 147 $(74 \%)$ out of 232 respondents had partnership experience. It appears that partnership is a common business practice among SMEs in architectural design services in Turkey. A collaboration-friendly culture indicates that SMEs are aware of the advantages of partnerships which provide win-win situations for all parties if managed correctly and professionally.

In addition to being a member of the Chamber of Architects (COA), 36 of the 232 respondents (18\%) confirmed that they also have active involvement in the organization of the COA. One hundred respondents $(43 \%)$ also reported that they are members of social organizations and $48(48 \%)$ stated that they have active roles in those organizations. Forty eight firms did not answer this question. The results tend to indicate that the participants appreciate the value of networking. Just as respondents are open to collaboration with partners, they are also aware of the importance of networking. Openness to interacting with people and to developing new relationships may create new business opportunities.

\section{Strategic planning}

The basic concepts of strategic planning and management were covered in the courses taught to the respondents before the survey questionnaire was administered. While 79 firms (34\%) did not perform strategic planning, $145(63 \%)$ had developed and used strategic plans (Table 2). Considering the small size of participating firms, the unpredictable nature of the industry, the proportion of SMEs that set long term strategic plans is quite high.

\section{CONCLUSIONS AND RECOMMENDATIONS}

The study analyzed the business management characteristics of SMEs in architectural design services business in Turkey. Improving the capabilities of these firms is critical for many reasons. In order to survive in global business environment they need to improve their business management skills up to the global business standards, therefore they stay competitive and they continue providing employment and contribute to the economy of the country that they operate. Their survival and growth is critical because SMEs are responsible for considerable amount of employment. The necessity of global integration is also dictated by foreign firms' entry from developed nations to fast developing economies like Turkey. These firms need to cooperate with local firms in this process. Identifying the strengths and weaknesses of local architectural design SMEs was the first step for improving their capabilities to facilitate their integration to globalization. According to the findings, the strengths and its related discussions for SMEs in architectural design business can be summarized as follows:

1. New and advanced technologies can easily be adopted by SMEs as long as their commercial benefits are well understood by the users, as evidenced by the extensive diffusion of CADD technologies. The ability to adopt new technologies is the major advantage in the process of being integrated to global business system. This is the indication that when a large international AEC firm launches a business in Turkey, architectural design SMEs have the capability to adopt new technologies which can be requested by entrant firms.

2. There is a strong awareness of the importance of business development skills. The overwhelming majority of the respondents suggest that business development and marketing related courses must be included in the curricula of architecture and related fields and more than half of the SMEs conduct marketing research despite their limited size.

3. Partnership is a common business practice in SMEs. Having a collaboration-oriented culture is important especially in global business practices. Ability to work professionally in partnership settings is the first requirement to successfully implement business with entrant firms. The SMEs benefit from the collaboration in terms of gaining global business practice experience and entrant firms successfully conduct their projects in the fast developing host country.

4. Almost two thirds of the SMEs make long-term strategic plans despite their limited size and the unpredictable nature of the industry. Ability to think and plan strategically provides companies to concentrate on long term goals. At the same time, companies gain perspective and are able to see the big picture. In order to understand and operate in global business environment, companies need to have a strategic planning culture.

The weaknesses and its related discussions for the SMEs in the Turkish AEC industry can be summarized as follows:

i. SMEs lack the skills to manage organizational growth. This is clearly observed in the survey results that the number of firms with employees between 1 and 5 is overwhelmingly high. Since there is a deficiency in managing the growth, there is also a constant risk of not establishing operational procedures at the professional 
level. This is a risk in a global business setting. Architectural design SMEs need to concentrate more on the professional business management skills. This concentration will lead them to develop appropriate growth strategies. The problem goes back to basic training scope. Business management related courses must be included in the curricula of architecture. Continuous education programs must include related courses for architects to develop skills in business management.

ii. The use of computerized project management by SMEs is low. Commercial time-saving technologies and advanced management applications are not well established mainly because of low wages. The SMEs in fast developing economies like Turkey obtains a competitive edge by providing faster service and delivery with relatively cheap labor. Mistakes can be tolerated since making corrections can be cheaper. Although the low wages seem to provide an advantage, in order to be integrated to global business system, this strategy does not seem to be right. Proven that the SMEs have the ability to adopt new technologies easily, advanced project management will be embraced unless wages become higher.

iii. There is no formal project administration system in one third of the SMEs an indication that the projects are performed without formal communication procedures with external stakeholders. This is a business management culture issue. Although it requires fundamental restructuring in overall business platform, two thirds of the survey participants indicated that they conduct their projects by using a formal project administration system. In order to make formal administration systems as common systems in business applications, fair competitiveness needs to be increased. Unless profit margins are tightened and serious legal implications are in place the use of formal project administration systems will not be widespread.

iv. The low level of specialization in SMEs indicates the absence of focused and in-depth expertise in many aspects of the business. On the other hand, most SMEs are involved in several activities in addition to architectural design. Specialty expertise is important in order to obtain best results. Due to complexities in design practices, architects sometimes find themselves providing different services other than design such as construction services. This situation limits specialization in specific aspects of the profession. This is obviously a threat in the process of being integrated to global business practices. Specialty expertise enhances the quality of services.

v. Despite a good understanding of the benefits of efficient business development, the majority of the SMEs rely on repeat clients based on the existing client portfolio, which is not the best strategy in the long term. They are reluctant on being active in business development since they mainly consider themselves design or construction services providers. Architectural SMEs need to convince themselves that any type of profession requires business development skills. Lacking these skills will be costlier in global business environment. Knowing how to reach new clients is critical since global business platform consists of many opportunities.

\section{REFERENCES}

Aktas R (2006) <http://www.ihale.gov.tr/semp1/sunumlar/ KOBILER\%20VE\%20KAMU\%20ALIMLARI_dosyalar/frame.htm\#s lide0276.htm>.

Babiarz BA (2000). Marketing Research: The Road to Profits, Marketing Handbook for the Design and Construction Professional, BNI Building News, Los Angeles, CA.

Chinowsky PS, Byrd MA (2001). Strategic Management in Design Firms. J. Manage. Engineer., 127(1): $32-40$.

Gursoy M (2006). EU Integration and Turkish SMEs, $<$ http://www.developmentandtransition.net/uploads/issuesAttachm ents/14/DevAndTransFour Web.pdf>.

Jones RF (2001). Power Marketing of Architectural Services. Trafford, Canada.

Katsanis CJ, Katsani LP (2001). An Examination of Business Development Activities and Implications for Marketing in the AEC Industry.

<http://www.brookes.ac.uk/other/conmark/IJCM/Vol_03/Vol3 paper3-author-info.htm>

Knight G (2000). Entrepreneurship and Marketing Strategy: The SME under Globalization, J. Int. Market., 8(2): 12 - 32

Knight G (2001). Entrepreneurship and Strategy in the International SME, J. Int. Manage., 7(2001): 155 - 171

Langford D, Male S (2001). Strategic Management in Construction, Second Edition, Blackwell Science, Great Britain

Mawhinney M (2001). International construction, Blackwell Science Malden, MA.

Nitithamyong P, Skibniewski MJ (2004). Web-based Project Management Systems: How to make them successful? Automat. Construct., 13(2004): $491-506$.

OECD (2004). Small and Medium-Sized Enterprises in Turkey: Issues and Policies, <http://www.oecd.org/dataoecd/5/11/31932173.pdf>.

Rojas E, Songer AD (1999). Web-centric systems: A new paradigm for collaboration engineering. J. Manage. Eng., 15(1): 39 - 45

Root FR (1994). Entry Strategies for international Markets, Lexington Books, New York, NY.

Sarshar M, Isikdag U (2004). A Survey of ICT use in the Turkish Construction Industry, Engineer. Construct. Architect. Manage., 11(4): 238 - 247

Smartmarket Report (2007). Interoperability in the Construction Industry, McGraw-Hill Construction, New York, NY.

TUSIAD Report (2002). Turkiye'de Girisimcilik, Entrepreneurship in

Turkey, <http://www.tusiad.org/FileArchive/girisimcilik.pdf>.

Yilmaz F (2003). SMEs in Turkey, $<$ https://www.isbank.com.tr/dosya/ekon-tr_kobiler2004.pdf>. 